\title{
FMR study of samples obtained by nitriding and nitrides reduction of nanocrystalline iron
}

\author{
JANuSZ TYPEK $^{1 *}$, Nikos Guskos ${ }^{1}$, GRZEGORZ ZOLNIERKIEWICZ ${ }^{1}$, AlEKSANDER Guskos ${ }^{1}$, \\ Karolina Kielbasa ${ }^{2}$, Rafal Pelka ${ }^{2}$, WAlerian ArabCZyK ${ }^{2}$ \\ ${ }^{1}$ Institute of Physics, West Pomeranian University of Technology, al. Piastow 48, 70-311, Poland \\ ${ }^{2}$ Institute of Inorganic Chemical Technology and Environmental Engineering, West Pomeranian University of Technology, \\ Pulaskiego 10, 70-322 Szczecin, Poland
}

\begin{abstract}
Samples obtained by nitriding of promoted nanocrystalline iron and the nitrides reduction at various nitriding potential in terms of thermodynamic parameters were investigated by electron paramagnetic resonance/ferromagnetic resonance (EPR/FMR) method at room temperature. Experimental FMR spectra were fitted by the Dysonian-type resonance lines arising from the presence of different $\mathrm{Fe}-\mathrm{N}$ phases. The obtained FMR parameters allowed us to identify the component phases and to determine their magnetic properties. In general, the proposed simple method of decomposition of the FMR spectra produced results on the phase content in investigated samples that were consistent with XRD measurements and additionally, magnetic characteristics of the studied nanomagnets.
\end{abstract}

Keywords: FMR; nitriding; $\mathrm{Fe}-\mathrm{N}$ phases; magnetic properties

(C) Wroclaw University of Technology.

\section{Introduction}

Nitriding technique is one of the most important surface-modification techniques used for solid materials. Nitriding reaction is of great industrial interest due to its influence on the surface hardness as well as wear and abrasive resistance of the nitrided surface [1-10]. Nitriding technology has been widely used also in improving material fatigue life, corrosion resistance and resistance of surface to softening effect. The behavior and properties of nitrogen in metals has been investigated extensively by several scientific groups because of its relevance, for instance, in catalysis processes.

The nitriding process as well as nitrides reduction process were investigated in our group by making use of a differential tubular reactor equipped with thermogravimetric measurements. Details of the processes have been presented in the literature [11-13]. During nitriding process a chain of reactions occurs: nitriding reaction, penetration of

*E-mail: typjan@zut.edu.pl the chemisorbed atomic nitrogen to the bulk of the lattice of iron $(\alpha-\mathrm{Fe}(\mathrm{N}))$, phase transition to iron nitride $\gamma^{\prime}-\mathrm{Fe}_{4-\mathrm{x}} \mathrm{N}$ and next, to $\varepsilon-\mathrm{Fe}_{\mathrm{x}} \mathrm{N}$ when a critical bulk concentration of nitrogen is reached. During nitrides reduction the surface reaction of catalytic ammonia decomposition takes place. There are a lot of various phases present in the $\mathrm{Fe}-\mathrm{N}$ system and their crystal structures and magnetic properties change with nitrogen concentration [1416]. It is known that nitrogen-poor phases, such as $\gamma^{\prime}-\mathrm{Fe}_{4} \mathrm{~N}, \varepsilon-\mathrm{Fe}_{2-3} \mathrm{~N}, \alpha^{\prime}-\mathrm{Fe}_{8} \mathrm{~N}$ and $\alpha^{\prime \prime}-\mathrm{Fe}_{16} \mathrm{~N}_{2}$, are ferromagnetic stoichiometric compounds. On the other hand, the $\varepsilon-\mathrm{Fe}_{\mathrm{x}} \mathrm{N}(2<\mathrm{x}<2.3)$ phase is paramagnetic at room temperature (RT) and ferromagnetic below RT, and its Curie temperature decreases when the iron content $\mathrm{x}$ decreases.

Recently, we have investigated methane decomposition on nanocrystalline iron, promoted with small amounts of calcium, aluminum and potassium oxides [17]. Ferromagnetic resonance (FMR) spectra of $\mathrm{Fe}_{3} \mathrm{C}$ and $\alpha$-Fe nanoparticles have been recorded at room temperature in the samples subjected to different carburization levels. They have 
been analyzed in terms of four components of Callen lineshape and revealed anisotropic magnetic interaction in two types of nanoparticles. It was determined that the magnetocrystalline anisotropy is the main contributor to the observed anisotropy, the shape anisotropy being of secondary importance. Magnetic nanoparticle agglomerates of iron and iron carbide located in a non-magnetic matrix have been already intensively studied by using FMR method [17-24].

Most of previous studies gave comprehensive knowledge about the behavior of nitrogen in bulk or coarse-grained iron. However, details on nitriding of nanocrystalline iron are presently poorly known, thus, it is required to explain the substance of this method. The aim of this study was to determine the phase content of samples obtained at different stages of nitriding process and nitrides reduction of nanocrystalline iron, using only FMR/EPR spectra of these samples registered at RT. The obtained results were compared and discussed with previously carried out XRD measurements on these samples. Moreover, some magnetic characteristics of these phases revealed in the studied samples were determined.

\section{Experimental}

Recrystallization of nanocrystalline iron occurs at temperatures higher than $300{ }^{\circ} \mathrm{C}$, thus, the material is promoted with aluminum and calcium oxides to prevent that undesirable effect. A mixture containing magnetite and small amounts of aluminum and calcium oxides as well as iron as reductor was fused at $1600{ }^{\circ} \mathrm{C}$. After melting and cooling, the prepared frozen lava was crumbled (grains size of 1.0 to $1.2 \mathrm{~mm}$ ) and reduced polithermally by hydrogen. The obtained sample contained only one crystallographic phase - magnetite - the promotors exhibited amorphous phases. As a result of the reduction, iron with nanocrystalline structure was produced. Detailed chemical composition of the prepared sample was described in the literature $[25,26]$. The nanocrystalline samples were pyrophoric, thus, the material had to be passivated to form a passive layer of iron oxide on the grain surface to prevent oxidation. Chemical composition of the studied materials was determined by inductively coupled plasma method (ICP - using OES Perkin Elmer spectrometer, type Optima 5300DV). Apart from metallic iron, the samples contained the following oxides: 3.3 wt. $\% \mathrm{Al}_{2} \mathrm{O}_{3}, 2.8$ wt. $\%, \mathrm{CaO}$ $0.65 \mathrm{wt} \% \mathrm{~K}_{2} \mathrm{O}$. It was found that the catalyst structure depends on temperature but after stabilization in a given temperature the surface is stable and remains unchanged during the process of nitridingreduction cycles. Aluminum, calcium and potassium oxides occupy inter-granular spaces that stay unchanged. Fig. 1 shows SEM images and element mapping of distribution of elements on the surface of a studied sample after the reduction process. In the images with $100 \mu \mathrm{m}$ scale it can be seen that the promoters distribution in the sample after reduction process has much in common with that sample before reduction process. In turn, in the image with $1 \mu \mathrm{m}$ scale (Fig. 1, left lower row) we can observe single $\alpha$-iron crystallites. The value of specific surface area $-12 \mathrm{~m}^{2} / \mathrm{g}$ - was determined by means of thermal desorption method (AutoChem II 2920 apparatus by Micromeritics Company). XRD studies were carried out on the Phillips X'Pert PRO diffractometer (X-ray diffraction apparatus with cooper lamp). Powder diffractograms for the materials with different nitriding levels obtained during nitriding of nanocrystalline iron were already presented in a recent paper [27]. An average size of iron nanocrystallites was determined by Scherrer's method and it was below $60 \mathrm{~nm}$. Crystallites size distribution was calculated by a new method, applicable to systems, where chemical reaction between the solid and the gas phase occurs [28, 29]. The size distribution of nanoparticles was very similar in all studied samples. The obtained nanoparticles were strongly agglomerated.

The nitriding process and the nitrides reduction process were investigated at the temperature of $400{ }^{\circ} \mathrm{C}$ under atmospheric pressure. In the gas nitriding process, the nitriding potential is used to describe nitridability of nitriding atmosphere which contains ammonia. The nitriding potential is defined as $\mathrm{p}=\frac{\mathrm{p}_{\mathrm{NH}_{3}}}{\mathrm{p}_{\mathrm{H}_{2}}^{3 / 2}}$, where $\mathrm{p}_{\mathrm{NH}_{3}}$ and $\mathrm{p}_{\mathrm{H}_{2}}$ are the partial pressures of the ammonia and hydrogen gases, respectively. In the nitriding process the nitriding 


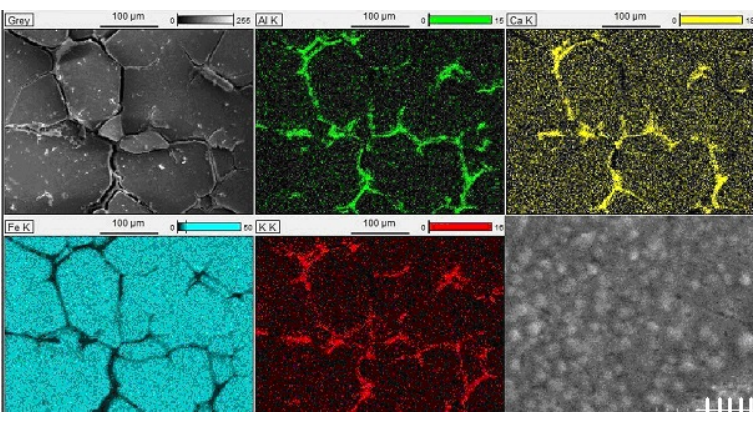

Fig. 1. SEM images and mapping of elements distribution on the surface of studied sample after the reduction process.

potential was increasing. The inlet ratio of ammonia to hydrogen $\left(\frac{\mathrm{X}_{\mathrm{H} 2}}{\mathrm{X}_{\mathrm{NH} 3}} \in(\infty \div 0)\right)$ was changed when the stationary state was achieved. In that particular state only catalytic ammonia decomposition reaction was running. After several hours, the mass of solid sample did not change, therefore, it allowed reaching an equilibrium between the gas and solid phases. Gas mixture composition was changing but the total gas load was constant $\left(0.0025 \mathrm{~m}^{3} \cdot \mathrm{s}^{-1} \cdot \mathrm{kg}^{-1}\right)$. The values of partial pressure of gas reactants were determined on the basis of the results of hydrogen content measurements as well as the material balance of the reactor. The studies of the reduction process of nitrides started up when the maximum nitriding degree of the solid sample was achieved $\left(100 \% \mathrm{NH}_{3}\right.$ in the reactor). Decrease of nitriding potential was obtained by changing the gas phase composition until pure hydrogen was introduced to the reactor. During the reduction process, stationary states exist, as well. The relation between nitriding degree of a solid sample and the nitriding potential exists in the stationary states during both processes. Different compositions of solid samples at given nitriding potential can be achieved, in respect to the studied processes: nitriding of iron or nitrides reduction.

FMR measurements were carried out using Bruker E 500 spectrometer working in the X-band $(v=9.45 \mathrm{GHz})$ at $100 \mathrm{kHz}$ magnetic field modulation. The six investigated samples, designated as samples 1 to 6 , were taken from different stages of the nitriding and nitride reduction. The FMR study was performed at room temperature.

\section{Results and discussions}

XRD patterns for a few investigated samples and a reference sample (before nitriding, designated as 0) are shown in Fig. 2. On the basis of XRD studies it is seen that the areas, where phase composition of solid samples was changing during nitriding and reduction processes were obtained. It can be observed that during the nitriding process the areas of various phases coexist in a wide range of nitriding potential. During the first phase of nitriding the observed nitriding level is relatively low, less than $0.015 \mathrm{~mol}_{\mathrm{N}} / \mathrm{mol}_{\mathrm{Fe}}$, which corresponds to the nitrogen dissolving and ammonia adsorption on the surface of the iron, i.e. creation of solid solution of nitrogen in the iron $(\alpha-\mathrm{Fe}(\mathrm{N}))$. This is followed by formation of a new phase, thus, two phases exist simultaneously in the sample: $\alpha-\mathrm{Fe}(\mathrm{N})$ and $\gamma^{\prime}-\mathrm{Fe}_{\mathrm{x}} \mathrm{N}$. At the further nitriding stage only one phase exists: $\gamma^{\prime}-\mathrm{Fe}_{4-\mathrm{x}} \mathrm{N}$, where $\mathrm{x}$ decreases with the increase of the nitriding potential. After that, continuation of saturating of the nitride by nitrogen causes two phases to exist simultaneously: $\gamma^{\prime}-\mathrm{Fe}_{4-\mathrm{x}} \mathrm{N}$ and $\varepsilon-\mathrm{Fe}_{\mathrm{x}} \mathrm{N}$. It is followed by continuous saturating of the $\varepsilon-\mathrm{Fe}_{\mathrm{X}} \mathrm{N}$ by nitrogen.

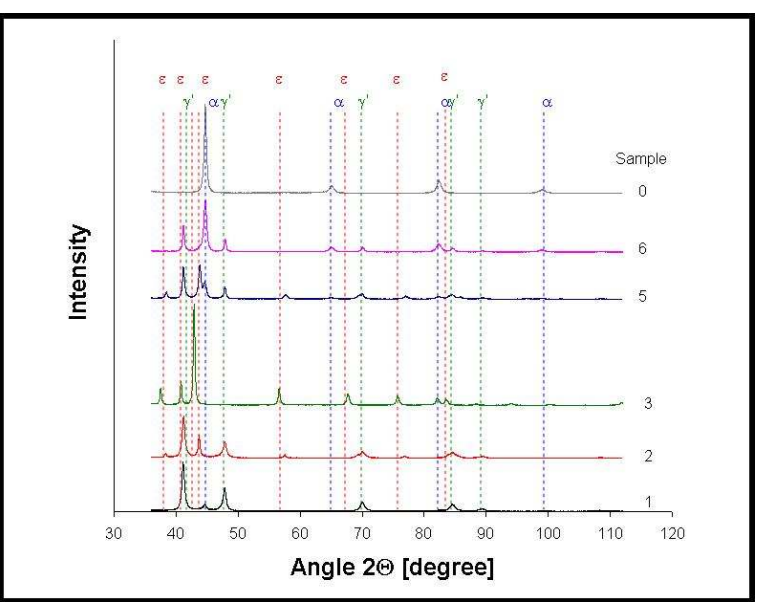

Fig. 2. XRD patterns of investigated samples $(1,2,3,5$, 6, designation as in Fig. 3) and reference sample 0 (not subjected to nitriding).

Fig. 3 shows the dependence of nitrogen to $\alpha$-iron ratio on logarithm of nitriding potential. During nitriding of nanocrystalline iron and 
reduction of nanocrystalline nitrides as a function of potential, the hysteresis loop is observed.

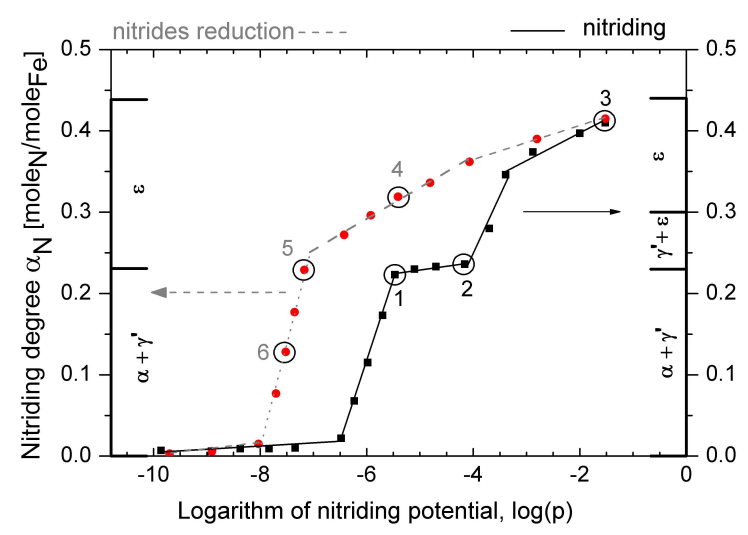

Fig. 3. The dependence of nitriding degree on logarithm of nitriding potential for the iron nitriding (solid line) and iron nitrides reduction (dashed line). Phase composition obtained from XRD measurements is indicated on both vertical axes.

The registered magnetic resonance spectra of six studied samples (Fig. 4) were classified as EPR (sample 3) and FMR (samples 1, 2, 4 to 6) spectra. The EPR spectrum of paramagnetic $\varepsilon-\mathrm{Fe}_{\mathrm{x}} \mathrm{N}$ phase (at room temperature) is very weak in comparison with FMR spectra of ferromagnetic $\alpha-\mathrm{Fe}(\mathrm{N})$ and $\gamma^{\prime}-\mathrm{Fe}_{4-\mathrm{x}} \mathrm{N}$ phases. Thus, the paramagnetic resonance line of $\varepsilon-\mathrm{Fe}_{\mathrm{x}} \mathrm{N}$ phase can only be seen in sample 3 in which, according to XRD measurements, ferromagnetic $\alpha-\mathrm{Fe}(\mathrm{N})$ and $\gamma^{\prime}-\mathrm{Fe}_{4-\mathrm{x}} \mathrm{N}$ phases were absent. In the other samples strong ferromagnetic resonance line masked much weaker paramagnetic signal from $\varepsilon-\mathrm{Fe}_{\mathrm{x}} \mathrm{N}$ phase, even if that phase was detected by XRD (samples 2, 4 and 5).

EPR spectrum of sample 3 was fitted by two lines of Lorentzian lineshape. The expression for the Lorentzian lineshape (in absorption mode) as a function of the magnetic field is:

$$
P_{\text {Lor }}=\frac{P_{\max }}{1+\left(\frac{H-H_{0}}{0.5 \cdot \Delta H}\right)^{2}}
$$

where $\mathrm{P}_{\max }$ is the maximum power absorbed at resonance, $\mathrm{H}_{0}$ is the resonance field and $\Delta \mathrm{H}$ is the full width at half-maximum of the resonance line.

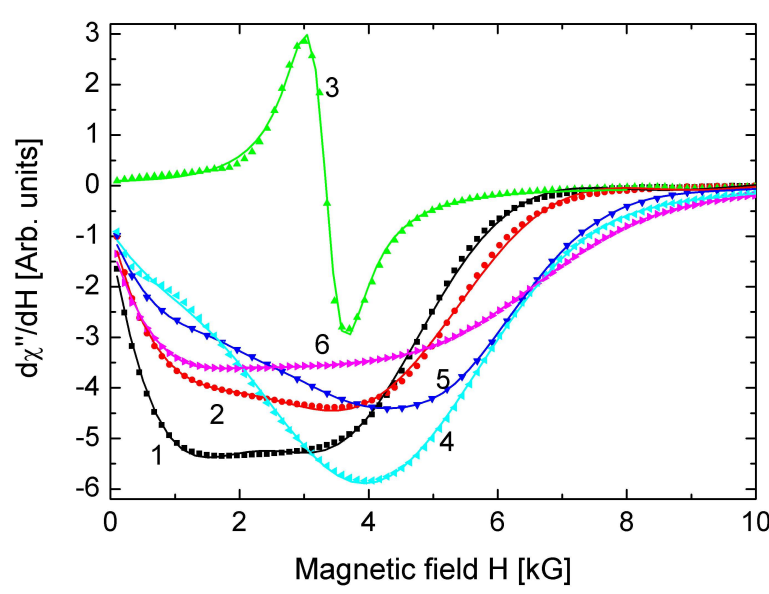

Fig. 4. Experimental (symbols) and fitted (solid line) magnetic resonance spectra of samples 1 to 6 .

These two lines represent parallel and perpendicular magnetic components of the anisotropy field of $\varepsilon-\mathrm{Fe}_{\mathrm{x}} \mathrm{N}$ phase.

In the analysis of FMR spectra of other ferromagnetic samples it was assumed that assembling of nanoparticles along randomly distributed uniaxial anisotropy axes occurred. In that case, for different orientations of nanoparticle anisotropy axis with respect to an external static magnetic field direction, the observed FMR resonance line is shifted to lower or higher fields depending on that orientation. For the nanoparticle anisotropy axis in the direction of static field (parallel orientation), the position of FMR lines shifts to smaller fields, while for anisotropy axis perpendicular to external magnetic field (perpendicular orientation) it shifts to higher fields [30]. Thus, the observed resonance line for an ensemble of nanoparticles with randomly distributed orientations of the anisotropy axis is a superposition of such shifted absorption curves. To simplify the analysis we have made a crude approximation of such complex FMR line as a superposition of only two components attributed to parallel and perpendicular orientations of nanoparticle anisotropy axes in respect to external static field.

FMR spectra of samples 1, 2, 4, 5, and 6 were fitted by four lines of Dysonian lineshape each. Feher and Kip [31] analyzed the shape of the resonance line using Dyson theory and applied it in case of low conductivity samples with a skin layer 
compared to the layer thickness. The following expression for the Dysonian line has been used [32]:

$$
P_{D y s}=\frac{P_{L o r}}{2}\left(1-\frac{H-H_{0}}{0.5 \cdot \Delta H}\right)
$$

Attempts to fit the FMR spectra with Callen lineshape components were unsuccessful because the obtained values of spectral parameters were unrealistic (resonance fields and linewidths greater than $20 \mathrm{kG}$ ). The reason for much better fit by Dysonian lines in comparison to Callen lines in case of our current samples (as opposed to previous samples obtained by methane decomposition on nanocrystalline iron) could be explained by their higher electrical conductivity. FMR spectrum of each sample was successfully fitted with four component lines of Dysonian lineshape (Fig. 4). An attempt to fit it with smaller number of components was unsatisfactory. These lines were ascribed to the presence of two different phases in the ferromagnetic samples: $\left(\alpha-\mathrm{Fe}(\mathrm{N})\right.$ and $\left.\gamma^{\prime}-\mathrm{Fe}_{4-x} \mathrm{~N}\right)$. Two lines were attributed to each phase: these lines arose due to magnetic anisotropy, therefore, they are parallel and perpendicular components of the anisotropy field.

The parameters in Table 1 were calculated by the least-square fitting of the sum of four/two Dysonian/Lorentzian components to the experimental FMR/EPR spectra. To make the obtained values more comprehensive, graphical presentation of two spectral parameters (resonance field, linewidth) for each component in all investigated samples is presented in Fig. 5. Each rectangle in that figure collects components arising from the same phase. The difference of the resonance fields of both components (one in high $\mathrm{H}_{\mathrm{h}}$ (perpendicular orientation) and the other in low field $\mathrm{H}_{\mathrm{L}}$ (parallel orientation)) arising from the same phase could be correlated with the effective uniaxial anisotropy field $\mathrm{H}_{\mathrm{a}}$ of that phase by using the relation [33]:

$$
H_{a}=\frac{2}{3}\left(H_{h}-H_{L}\right)
$$

where $\mathrm{H}_{h}$ and $\mathrm{H}_{\mathrm{L}}$ are the of high and low resonance fields arising from a particular phase. Calculated values of $\mathrm{H}_{\mathrm{a}}$ for different phases in all investigated samples are presented in Table 2. It can be seen that magnetic anisotropy of $\alpha-\mathrm{Fe}(\mathrm{N})$ phase is roughly three times bigger than $\gamma^{\prime}-\mathrm{Fe}_{4-\mathrm{x}} \mathrm{N}$ phase. This is reasonable as the magnetism of the former phase must be stronger than that of the last phase due to higher concentration of magnetic iron ions.

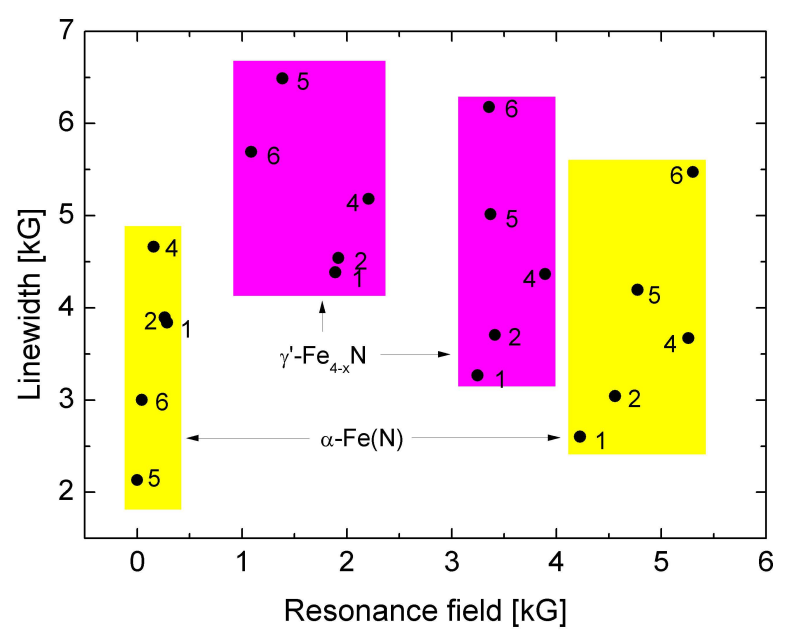

Fig. 5. Graphical presentation of two spectral parameters (resonance field, linewidth) for each component in all investigated samples. Each rectangle collects components arising from the same phase.

In Table 2 the relative integrated intensity ratio of $\alpha-\mathrm{Fe}(\mathrm{N}) / \gamma^{\prime}-\mathrm{Fe}_{4-\mathrm{x}} \mathrm{N}$ phases calculated from FMR spectra is also shown. The integrated intensity of a particular phase is calculated as the sum of two similar terms (as there are two components for each phase): each term is a product of a signal amplitude and a square of the linewidth, $\mathrm{I}=\mathrm{A} \cdot \Delta \mathrm{H}^{2}$. It is supposed that the integrated intensity is proportional to the concentration of a particular phase. From the obtained numbers it could be judged that during the nitride reduction process the amount of $\alpha-\mathrm{Fe}(\mathrm{N})$ phase relative to the $\gamma^{\prime}-\mathrm{Fe}_{4-\mathrm{x}} \mathrm{N}$ phase is smaller than during the nitriding process. Thus, the FMR/EPR measurements are in general in agreement with XRD results, although the relative amounts of detected phases might differ.

\section{Conclusions}

When the paramagnetic and ferromagnetic phases are present in a sample only lines from 
Table 1. Values of the FMR/EPR parameters $\left(\mathrm{A}_{\mathrm{i}}-\right.$ amplitude, $\mathrm{H}_{0 \mathrm{i}}$ - resonance field, $\Delta \mathrm{H}_{\mathrm{i}}-$ linewidth) for four components (two in case of sample 3) of the observed spectra. Each component has been attributed to a specific phase detected in XRD measurements. In each case (except for sample 3 with Lorentzian lineshape) the Dysonian lineshape of a particular component was assumed. Subscripts $\mathrm{L}$ and $\mathrm{h}$ stand for low and high field components of a specific phase, respectively.

\begin{tabular}{|c|c|c|c|c|c|c|c|c|c|c|c|c|}
\hline \multirow[t]{2}{*}{ Sample } & \multicolumn{12}{|c|}{ Parameter } \\
\hline & $\begin{array}{c}\mathrm{A}_{1} \\
\text { [a.u.] }\end{array}$ & $\begin{array}{l}\mathrm{H}_{01} \\
{[\mathrm{G}]}\end{array}$ & $\begin{array}{c}\Delta \mathrm{H}_{1} \\
{[\mathrm{G}]} \\
\end{array}$ & $\begin{array}{c}\mathrm{A}_{2} \\
{[\mathrm{a} . \mathrm{u}]}\end{array}$ & $\begin{array}{l}\mathrm{H}_{02} \\
{[\mathrm{G}]} \\
\end{array}$ & $\begin{array}{c}\Delta \mathrm{H}_{02} \\
{[\mathrm{G}]} \\
\end{array}$ & $\begin{array}{c}\mathrm{A}_{3} \\
\text { [a.u.] }\end{array}$ & $\begin{array}{l}\mathrm{H}_{03} \\
{[\mathrm{G}]} \\
\end{array}$ & $\begin{array}{c}\Delta \mathrm{H}_{03} \\
{[\mathrm{G}]} \\
\end{array}$ & $\begin{array}{c}\mathrm{A}_{4} \\
\text { [a.u.] }\end{array}$ & $\begin{array}{l}\mathrm{H}_{04} \\
{[\mathrm{G}]} \\
\end{array}$ & $\begin{array}{l}\mathrm{H}_{04} \\
{[\mathrm{G}]} \\
\end{array}$ \\
\hline \multirow{2}{*}{1} & $8.8(1)$ & $285(5)$ & $3840(9)$ & $1.1(1)$ & $4225(5)$ & $2600(5)$ & $6.7(1)$ & $1890(5)$ & $4390(5)$ & $2.7(1)$ & $3250(5)$ & $3270(5)$ \\
\hline & \multicolumn{3}{|c|}{$(\alpha-\mathrm{Fe}(\mathrm{N}))_{\mathrm{L}}$} & \multicolumn{3}{|c|}{$(\alpha-\mathrm{Fe}(\mathrm{N}))_{\mathrm{h}}$} & \multicolumn{3}{|c|}{$\left(\gamma^{\prime}-\mathrm{Fe}_{4-\mathrm{x}} \mathrm{N}\right)_{\mathrm{L}}$} & \multicolumn{3}{|c|}{$\left(\gamma^{\prime}-\mathrm{Fe}_{4-\mathrm{x}} \mathrm{N}\right)_{\mathrm{h}}$} \\
\hline \multirow{2}{*}{2} & $6.9(1)$ & $260(5)$ & $3900(5)$ & $1.4(1)$ & $4560(5)$ & $3045(5)$ & $6.1(1)$ & $1920(5)$ & $4540(5)$ & $3.2(1)$ & $3410(5)$ & $3710(5)$ \\
\hline & \multicolumn{3}{|c|}{$(\alpha-\mathrm{Fe}(\mathrm{N}))_{\mathrm{L}}$} & \multicolumn{3}{|c|}{$(\alpha-\mathrm{Fe}(\mathrm{N}))_{\mathrm{h}}$} & \multicolumn{3}{|c|}{$\left(\gamma^{\prime}-\mathrm{Fe}_{4-\mathrm{x}} \mathrm{N}\right)_{\mathrm{L}}$} & \multicolumn{3}{|c|}{$\left(\gamma^{\prime}-\mathrm{Fe}_{4-\mathrm{x}} \mathrm{N}\right)_{\mathrm{h}}$} \\
\hline \multirow{2}{*}{3} & $30(1)$ & $3340(5)$ & $320(5)$ & $1.7(1)$ & $2910(5)$ & $1960(5)$ & - & - & - & - & - & - \\
\hline & \multicolumn{3}{|c|}{$\left(\varepsilon-\mathrm{Fe}_{\mathrm{x}} \mathrm{N}\right)_{\mathrm{h}}$} & \multicolumn{3}{|c|}{$\left(\varepsilon-\mathrm{Fe}_{\mathrm{X}} \mathrm{N}\right)_{\mathrm{L}}$} & \multicolumn{3}{|c|}{-} & \multicolumn{3}{|c|}{-} \\
\hline \multirow{2}{*}{4} & 7.1(1) & $155(5)$ & $4665(5)$ & $1.9(1)$ & $5260(5)$ & $3680(5)$ & $6.5(1)$ & $2210(5)$ & $5185(5)$ & $4.1(5)$ & $3890(5)$ & $4370(5)$ \\
\hline & \multicolumn{3}{|c|}{$(\alpha-\mathrm{Fe}(\mathrm{N}))_{\mathrm{L}}$} & \multicolumn{3}{|c|}{$(\alpha-\mathrm{Fe}(\mathrm{N}))_{\mathrm{h}}$} & \multicolumn{3}{|c|}{$\left(\gamma^{\prime}-\mathrm{Fe}_{4-\mathrm{x}} \mathrm{N}\right)_{\mathrm{L}}$} & \multicolumn{3}{|c|}{$\left(\gamma^{\prime}-\mathrm{Fe}_{4-\mathrm{x}} \mathrm{N}\right)_{\mathrm{h}}$} \\
\hline \multirow[b]{2}{*}{5} & $2.2(1)$ & $4770(5)$ & $4195(5)$ & $6.0(1)$ & $3370(5)$ & $5015(5)$ & $11.2(1)$ & $1385(5)$ & $6490(5)$ & $1.8(1)$ & $\sim 0(20)$ & $2135(5)$ \\
\hline & \multicolumn{3}{|c|}{$(\alpha-\mathrm{Fe}(\mathrm{N}))_{\mathrm{h}}$} & \multicolumn{3}{|c|}{$\left(\gamma^{\prime}-\mathrm{Fe}_{4-\mathrm{x}} \mathrm{N}\right)_{\mathrm{h}}$} & \multicolumn{3}{|c|}{$\left(\gamma^{\prime}-\mathrm{Fe}_{4-\mathrm{X}} \mathrm{N}\right)_{\mathrm{L}}$} & \multicolumn{3}{|c|}{$(\alpha-\mathrm{Fe}(\mathrm{N}))_{\mathrm{L}}$} \\
\hline \multirow{2}{*}{6} & $5.2(1)$ & $3355(5)$ & $6180(5)$ & $2.2(1)$ & $5300(5)$ & $5475(5)$ & $7.8(1)$ & 1090(5) & $5690(5)$ & $2.7(1)$ & $45(5)$ & $3000(5)$ \\
\hline & \multicolumn{3}{|c|}{$\left(\gamma^{\prime}-\mathrm{Fe}_{4-\mathrm{x}} \mathrm{N}\right)_{\mathrm{h}}$} & \multicolumn{3}{|c|}{$(\alpha-\mathrm{Fe}(\mathrm{N}))_{\mathrm{h}}$} & \multicolumn{3}{|c|}{$\left(\gamma^{\prime}-\mathrm{Fe}_{4-\mathrm{x}} \mathrm{N}\right)_{\mathrm{L}}$} & \multicolumn{3}{|c|}{$(\alpha-\mathrm{Fe}(\mathrm{N}))_{\mathrm{L}}$} \\
\hline
\end{tabular}

Table 2. Values of the effective uniaxial anisotropy field of different phases in investigated samples and relative integrated intensity ratio of $\alpha-\mathrm{Fe}(\mathrm{N}) / \gamma^{\prime}-\mathrm{Fe}_{4-\mathrm{x}} \mathrm{N}$ phases calculated from FMR spectra.

\begin{tabular}{|c|c|c|c|c|c|c|c|}
\hline & & \multicolumn{6}{|c|}{ Sample } \\
\hline & & 1 & 2 & 3 & 4 & 5 & 6 \\
\hline \multirow{3}{*}{$\begin{array}{c}\text { Effective uniaxial } \\
\text { anisotropy field } \\
\mathrm{H}_{\mathrm{a}}[\mathrm{G}]\end{array}$} & Phase & & & & & & \\
\hline & $\alpha-\mathrm{Fe}(\mathrm{N})$ & $2630(8)$ & $2860(8)$ & - & $3401(7)$ & $3182(8)$ & $3506(8)$ \\
\hline & $\gamma^{\prime}-\mathrm{Fe}_{4-\mathrm{x}} \mathrm{N}$ & $905(5)$ & $995(5)$ & - & $1123(5)$ & $1324(6)$ & $1512(6)$ \\
\hline $\begin{array}{r}\text { Relative integrated } \\
\mathrm{ph}\end{array}$ & $\begin{array}{l}\text { io of } \alpha-\mathrm{Fe}(\mathrm{N}) / \gamma^{\prime}-\mathrm{Fe}_{4-\mathrm{x}} \mathrm{N} \\
\text { IR spectra }\end{array}$ & $0.86(2)$ & $0.70(2)$ & - & $0.71(2)$ & $0.08(1)$ & $0.20(2)$ \\
\hline
\end{tabular}

the ferromagnetic phases are observed in the magnetic resonance spectra. For conducting samples the use of Dysonian lineshape is more appropriate than Callen lineshape in fitting magnetic resonance spectra. The anisotropic FMR spectra of ferromagnetic $\mathrm{Fe}-\mathrm{N}$ and $\gamma^{\prime}-\mathrm{Fe}_{4-\mathrm{x}} \mathrm{N}$ phases are correctly modelled by two components representing nanoparticles with their magnetization axes parallel and perpendicular to the external magnetic field. The effective uniaxial anisotropy field could be estimated from the separation of these components. Magnetic anisotropy of $\alpha-\mathrm{Fe}(\mathrm{N})$ phase is roughly three times bigger than that of $\gamma^{\prime}-\mathrm{Fe}_{4-x} \mathrm{~N}$ phase.
During nitride reduction process the amount of $\alpha-\mathrm{Fe}(\mathrm{N})$ phase relative to the $\gamma^{\prime}-\mathrm{Fe}_{4-\mathrm{x}} \mathrm{N}$ phase is smaller than during nitriding process. In general, the FMR/EPR measurements are in agreement with XRD results, although the relative amounts of detected phases might differ.

\section{References}

[1] XI Y.T., LiU D.X., Han D., Surf. Coat. Tech., 202 (2008), 2577.

[2] LAmpman S., Introduction to Surface Hardening of Steels, ASM Handbook Vol. 4, ASM International, 1994, p. 607. 
[3] O’Brien J.M., Plasma (Ion) Nitriding of Steels, ASM Handbook Vol. 4, ASM International, 1995, p. 944.

[4] Fontalvo G.A., Mitterer C., Reithofer G., Surf. Eng., 20 (2004), 474.

[5] Alphonsa I., Chainani A., Raole P.M., GanGUli B., John P.I., Surf. Coat. Tech., 150 (2002), 263.

[6] Zhan Q., Yu R., HE L.L., Li D.X., Thin Solid Films, 411 (2002), 225.

[7] Iwatsubo S., NaOe M., Vacuum, 66 (2002), 251.

[8] Abdellateef M.A., Heiden C., Lemke H., EIHoss ARY F.M., BAERner K., J. Magn. Magn. Mater, 256 (2003), 214.

[9] Zheng W.T., Sun C.Q., Prog. Solid State Chem., 34 (2006), 1.

[10] Wang L.L., Wang X., Zheng W.T., Ma N., Li H.B., Guan Q.F., Jin D.H., Zong Z.G., J. Alloy. Compd., 443 (2007), 43.

[11] Kielbasa K., Pelka R., Arabczyk W., J. Phys. Chem. A, 114 (2010), 4531.

[12] Pelka R., Kielbasa K., ArabczyK W., Cent. Eur. J. Chem., 9 (2011), 240.

[13] Moszynski D., Moszynska I., ArabCzyK W., Mater. Lett., 78 (2012), 32.

[14] Utsushikawa Y., NiIzuma K., J. Alloy. Compd., 222 (1995), 188.

[15] Coey J.M.D., Smith P.A.I., J. Magn. Magn. Mater., 200 (1999), 405.

[16] Costa-Kramer J.L., Borsa D.M., GarciaMartin J.M., Martin-GonZalez M.S., Boerma D.O., Briones F., Phys. Rev. B, 69 (2004), 144402.

[17] Helminiak A., ARABCZYK W., ZolNIERKIEWICZ G., Guskos N., TYPEK J., Rev. Adv. Mat. Sci., 29 (2011), 166.

[18] Narkiewicz U., Guskos N., ArabCzyK W., TYPEK J., BODZIONY T., KONICKI W., GĄSIOREK G., KUCHAREWICZ I., ANAGNOSTAKIS E.A., Carbon, 42 (2004), 1127.

[19] Guskos N., Anagnostakis E.A., Gasiorek G., TYPEK J., BODZIONNY T., NARKIEWICZ U., Arabczyk W., Konicki W., Mol. Phys. Rep., 39 (2004), 58.
[20] Guskos N., TyPeK J., NARkiewicz U., MaryNIAK M., AIDINIS K., Rev. Adv. Mater. Sci., 8 (2004), 10.

[21] Guskos N., TYPEK J., MARYNiAK M., NARKIEWICZ U., KUChareWICZ I., WrobEL R., Mater. Sci.-Poland, 23 (2005), 1001.

[22] BOdZIONY T., Guskos N., TYPEK J., Roslaniec Z., NARKIEWICZ U., MaryniaK M., Mater. Sci.-Poland, 23 (2005), 1055.

[23] Narkiewicz U., ArabczyK W., PeŁech I., Guskos N., TyPEK J., MARYNiAK M., WozniaK M.J., Matysiak H., Kurzydlowski K.J., Mater. Sci.-Poland, 24 (2006), 1067.

[24] Guskos N., MaryniaK M., TyPeK J., PeŁech I., NARKIEWICZ U., RosŁaniec Z., Kwiatkowska M., Solid State Phenom., 128 (2007), 213.

[25] Lendzion-Bieluń Z., Jędrzejewski R., Pol. J. Chem. Technol., 15 (2013), 27.

[26] LENDZION-BIEluń Z., ARABCZYK W., FIGURSKi M., Appl. Catal. B, 227 (2002), 255.

[27] Moszynska I., Moszynski D., ArabCzyK W., Przem. Chem., 88 (2009), 526.

[28] Pelka R., ARAbCZYK W., J. Nanomater, 2013 (2013), 645050

[29] Pelka R., Kielbasa K., Arabczyk W., Curr. Nanosci., 9 (2013), 711.

[30] Sukhov A., Usadel K.D., Nowak U., J. Magn. Magn. Mater., 320 (2008), 31.

[31] Feher G., Kip A.F., Phys. Rev., 98 (1955), 337.

[32] Veinger A.I., Zabrodskit A.G., Tsinek T.V., Goloshchapov S.I., Semenikhin P.V., Tech. Phys., 58 (2013), 1806.

[33] TYPeK J., WARDAl K., Zolnierkiewicz G., Guskos N., Sibera D., Narkiewicz U., J. Magn. Magn. Mater., 361 (2014), 18.
Received 2014-11-02 Accepted 2015-11-23 